\title{
The effect of cooking method on the physico-chemical characteristics and fatty acid composition in lamb longissimus dorsi muscle
}

\author{
Witold Rant*, Aurelia Radzik-Rant, Marcin Świątek, Roman Niżnikowski, Magdalena Ślęzak, \\ Żaneta Szymańska, Anna Morales-Villavicencio
}

Department of Animal Breeding and Production, Warsaw University of Life Sciences-SGGW, 02-786 Warsaw, Ciszewskiego St. 8, Poland

\section{A B S T R A C T}

\begin{abstract}
The effect of microwaving and roasting on physico-chemical characteristics and fatty acid composition in lamb longissimus dorsi muscle was investigated. The meat samples from 24 ram lambs of meat and wool purpose of Polish lowland sheep was analyzed. Lamb meat cooked in the microwave resulted in a higher cooking loss $(\mathrm{P}<0.05)$ compared to roasting. Compared to raw meat microwaving and roasting caused a significant increase in intramuscular fat, protein and collagen content. The samples cooked in microwave and roasted were brighter $(P<0.05)$ (higher $L^{*}$ values) in comparison to raw meat. Cooking did not change the contents of SFA and MUFA of meat only the sum of PUFA and PUFA/SFA ratio decreased $(P<0.05)$ for microwave treatment but did not change $n-6 / n-3$ index. The applied cooking methods did not affect significant changes in the content of C18:2 c9, t11 (CLA) isomer.
\end{abstract}

Keywords: Cooking methods; Meat quality; Fatty acid composition; Lambs

\section{INTRODUCTION}

Meat is the basis of a balanced diet due to the richness of nutrients. It is a source of high quality protein, many minerals such as zinc, selenium, iron and vitamins B12 and other B vitamins (Pereira and Vicente, 2013). It also provides vitamin A and folic acid (Biesalski, 2005). The fat content in meat as well as its composition is also very important for consumers (Wood et al., 2008).

The fat present in the muscle tissue is characterized by a high degree of saturation. This was often the reason for trying to eliminate meat from the human diet as an opportunity to inhibit the development of vascular diseases. However, in the intramuscular fat is the highest content of stearic and palmitic acid which are not the main cause of hypercholesterolemia (Tholstrup et al., 1994). While conjugated linoleic acid isomers (CLA), which the main source is ruminant and especially lamb meat, have undeniable anti-carcinogenic, immunomodulatory and antioxidant effects (Schmid et al., 2006). Equally valuable ingredient in lamb meat, from the point of view of human health, is also n-3 PUFA, occurring mainly in phospholipids as a component of cell membranes and membranous structures of muscle tissue. The content of these acids depends to a large extent on the diet of these animals (Nuernberg et al., 2008).

Meat and meat products require proper preparation before consumption. Heat treatment of meat by destroying pathogens ensures microbiological safety, and makes it more digestible (Kondjoyan et al., 2014; Tornberg, 2005). But meat processing can also contribute to the occurrence of a number of adverse changes in its composition and physicochemical properties (Aaslyng et al., 2003; Li et al., 2013; Serrano et al.,2007).

The loss of mass during processing involves not only the loss of water but also soluble proteins, vitamins and other nutrients with high nutritional value (Aaslyng et al., 2003). The temperature and time of cooking also affect protein denaturation, muscle fiber contraction and contraction and dissolution of connective tissue, thus affecting the reduction of meat tenderness, a feature extremely

\footnotetext{
${ }^{*}$ Corresponding author:

Witold Rant, Department of Animal Breeding and Production, Warsaw University of Life Sciences-SGGW, 02-786 Warsaw, Ciszewskiego St. 8. E-mail: witold_rant@sggw.pl
} 
important in consumer assessment (Li et al., 2013). Changes in the forms of myoglobin occurring during cooking affect the appearance of color, which is perceived by consumers as an indicator of freshness (Mancini and Hunt, 2005). Serrano et al. (2007) indicate that the cooking is not without effect on the lipids, especially the fatty acid content. The heat treatment may lead to loss of essential fatty acids, mainly due to their oxidation. Acids with a higher degree of unsaturation are more susceptible to oxidative processes (Bou et al., 2001). The degree of changes in meat depends on the cooking method. Choice of the appropriate method can reduce losses in nutrients content related to cooking time, heating speed and temperature (Pathare and Roskilly, 2016).

There is much less information about the response to the heat treatment of the nutrients contained in lamb compared to other types of meat. Lamb meat is a traditional food in many countries of the Mediterranean region. Significantly lower consumption of sheep meat is recorded in other European countries, especially in Eastern Europe. This is related to the relatively small sheep population in this area and the conviction about the difficulty and time-consuming in preparing of the lamb meat (Corcoran et al., 2001). Microwave cooking and roasting are one of the fastest and least labor-intensive methods of meat treatment. Thus, the aim of this study was to investigate the effect of these methods on changes in the chemical composition, selected physical characteristics and fatty acid profile of lamb meat.

\section{MATERIAL AND METHODS}

The animal experiment was conducted on the Experimental Farm of the Warsaw University of Life Sciences-SGGW. Ethical approval for the experiment was obtained from the Local Ethics Commission in Warsaw (consent form number WAW2_20/2016). The animals were maintained under uniform environmental conditions with constant zootechnical and veterinary supervision.

The 24 ram lambs of meat and wool purpose of Polish lowland sheep were used in the study. The lambs were nursed by ewes until 100 days of life. In this period apart from the unlimited access to the milk, from the second week of life, the lambs had unlimited access to meadow hay and crushed oat, which in the later period of rearing was replaced by grain mix. After weaning the lambs were maintained in group and fed a grain mix containing oat meal $(30 \%)$, barley meal $(40 \%)$, triticale meal $(30 \%)$ and grass hay according to standards.

The lambs were slaughtered at $32.0 \pm 0.5 \mathrm{~kg}$ of live weight. Before slaughter ram lambs were fasted for 12 hours and weighed. Then, they were taken to an abattoir and slaughtered according to Council Regulation (EC) No 1099/2009 of 24 September 2009. (Acts. Office. EU dated. 18.11.2009 L 303/1). Carcasses were suspended from the Achilles tendon and chilled at $4^{\circ} \mathrm{C}$ for $24 \mathrm{~h}$ and weighed. From the right and left side of each carcass the samples of longissimus dorsi muscle from lumbar region were collected, vacuum packed and transported in the refrigerator to the laboratory.

\section{Samples preparation and cooking treatment}

The samples were trimmed of visible connective and adipose tissues. The muscles from every animal were homogenized and divided into three equal samples of $100 \mathrm{~g}$ each. 24 pieces were intended for analysis as raw meat, the next 24 to roasting and 24 to microwave cooking. The samples adjusted to roasting and microwaving were formed of uniform size $(2 \mathrm{~cm}$ thick and $10 \mathrm{~cm}$ in diameter).

Roasting was conducted in a convection oven at $100^{\circ} \mathrm{C}$ until sample reached end point temperature $70^{\circ} \mathrm{C}$. Internal temperatures were monitored continuously in the approximate geometric center of each cut.

For microwave cooking, the samples were placed on a ceramic container in the center of the carousel of a microwave oven (Amica, AMM 17M70; $2450 \mathrm{MHz}, 700 \mathrm{~W}$ ), set at $700 \mathrm{~W}$. Two heating cycles of $2 \mathrm{~min}$ were used and the cut was turned over between cycles. Such heating procedure was developed during preliminary testing to attain a final temperature of $70^{\circ} \mathrm{C}$.

After cooking the samples were cooled $\left(40 \mathrm{~min}\right.$ at $\left.20-23^{\circ} \mathrm{C}\right)$ and manually wiped with a paper towel to remove visible exudates.

\section{Cooking loss}

The samples were weighed before $\left(\mathrm{M}_{\mathrm{i}}\right)$ and after $\left(\mathrm{M}_{\mathrm{f}}\right)$ cooking in order to determine the percentage of cooking loss (CL) using formulae:

$$
\mathrm{CL}=\left(1-\frac{\mathrm{Mf}}{\mathrm{Mi}}\right) \times 100
$$

\section{Meat color}

Instrumental color was measured on the surface of raw and cooked meat using Minolta CR-410 (Konica- Minolta) colorimeter. The following color coordinates were determined lightness $\left(\mathrm{L}^{*}\right)$, redness $\left(\mathrm{a}^{*}\right)$ and yellowness $\left(b^{*}\right)$, color saturation $\left(\mathrm{C}^{*}\right)$ and Hue $\left(\mathrm{H}^{*}\right)$. The color was measured at three different points of each sample. Before using the instrument was adjusted with a white reference tile. 


\section{Expressed juice}

The expressed juice was determined by Grau and Hamm (1953) method. Samples (0.3 g) of meat were placed on Whatman filter-paper No 1, and held under pressure of $2 \mathrm{~kg}$ for 5 minutes. The outlined area of the expressible juice and the meat film traced, and two areas were measured using planimeter. The results have been calculated in $\mathrm{cm}^{2} / \mathrm{g}$.

\section{Chemical composition of the meat}

The basic chemical composition of raw and cooked meat was determined by analyzing the contents of moisture, crude protein, intramuscular fat and collagen using a spectrometric technique with near-infrared transmission (NIR) method (PN-A-82109). The meat samples were homogenized in an Elektrolux DITO K35 processor. Afterward unified samples were placed in a measuring cell of FoodScan analyzer. The device uses the near-infrared transmission method within $850-1050 \mathrm{~nm}$ range and is fitted with ANN calibration developed using a model of artificial neural networks. The analysis is performed by indicating in the computer program the number of 16 measurements in the sample, then the program automatically calculates the average and presents the result.

\section{Fatty acid analysis}

The lipids from the muscle were extracted according to Folch et al. (1957). Saponification of fat made in $0.5 \mathrm{M}$ $\mathrm{KOH}$ in methanol and esterification in $10-$ percent $\mathrm{BF}_{3}$ in methanol. The fatty acid methyl esters extracted in the hexane.

Fatty acid profile of lipids was performed by gaschromatograph analysis using Agilent Technologies GC $6890 \mathrm{~N}$ instrument equipped with capillary column BP x70 (length $60 \mathrm{~m}$, internal diameter $0.22 \mathrm{~mm}$, film thickness $0.25 \mu \mathrm{m})$. Operation conditions were: helium gas (41 psi); a FID detector at $240^{\circ} \mathrm{C}$. The temperature programme was: $3 \mathrm{~min}$ at $130^{\circ} \mathrm{C}$, an increase to $235^{\circ} \mathrm{C}$ by $+2^{\circ} \mathrm{C} / \mathrm{min}$; 4 min at $235^{\circ} \mathrm{C}$.

The fatty acids were identified via reference material BCR 163 (Beef/Pig Fat Blend). The isomer linoleic acid (CLA) was determined by standard cis-9, trans-11 octadecadienoic acid-Larodon AB, Sweden.

\section{Statistical analysis}

Statistical analyses of the data obtained were performed using the SPSS 23.0 packet software (2016), based on a linear model that included the effect of cooking treatment. All effects were tested against residual middle-squares to determine the level of significance. Tukey's test was used for comparing mean values when F-test for main effect was significant. The results are presented as the least squares means for each trait (LSM) and standard error (SE).

\section{RESULTS AND DISCUSSION}

The two different meat cooking methods used in presented studies affected the cooking loss. Lamb meat subjecting to cooking in the microwave resulted in a greater loss of mass $(\mathrm{P}<0.05)$ compared to roasting (Table 1). The results are in agreement with those reported by Yarmand and Homayouni (2009), who also found the increase in cooking loss in semitendinosus muscle of lambs heated in microwave compared to the conventional cooking method. A statistically significant increase in the thermal loss in microwaved meat $(42.71 \%)$ compared to grilling $(32.64 \%)$ and boiling $(39.10 \%)$ was also reported by Alfaia et al. (2010) for beef. Also in the studies of Dominguez et al. (2014) on the foal meat was found, that microwave cooking resulted in the highest cooking loss. These findings are in agreement with other authors (Nikmaram et al., 2011; Yarmand et al., 2013), who obtained the greater cooking loss in meat heated in microwave. In turn, in research of Maranesi et al. (2005) a significantly higher cooking loss was observed during broiling compared to microwave cooking. The authors state, that noticeable proportion of the cooking loss of the broiled steaks was due to the cover, and seam fat rendering from the meat during cooking. The cooking loss depends on the mass transfer during thermal processing and is related to the cooking procedure and also to properties of raw meat (Gerber et al., 2009; Serrano et al., 2007). During microwave cooking high electromagnetic field, high power and relatively brief time cause quick protein denaturation, breaking down the texture matrix, quick protein destruction brought on thermal shock to the proteins, which eventually leads to a larger cooking loss (Yarmand and Homayouni, 2009).

Table 1: Effect of cooking method on cooking loss, expressed juice and selected nutrients

\begin{tabular}{|c|c|c|c|c|}
\hline \multirow[t]{2}{*}{ Trait } & Raw meat $(n=24)$ & Microwaving $(n=24)$ & Roasting $(\mathrm{n}=24)$ & SE \\
\hline & LSM & LSM & LSM & \\
\hline Cooking loss (\%) & - & $36.01^{b}$ & $31.12^{\mathrm{a}}$ & 1.11 \\
\hline Expressed juice $\left(\mathrm{cm}^{2} / \mathrm{g}^{-1}\right)$ & $9.75^{b}$ & $7.38^{a}$ & $6.51^{\mathrm{a}}$ & 0.60 \\
\hline Moisture (\%) & $75.28^{b}$ & $60.72^{\mathrm{a}}$ & $60.86^{a}$ & 0.53 \\
\hline Fat (\%) & $2.67^{b}$ & $7.53^{a}$ & $7.81^{a}$ & 0.38 \\
\hline Protein (\%) & $21.27^{b}$ & $30.29^{a}$ & $30.13^{a}$ & 0.34 \\
\hline Collagen (\%) & $1.30^{\mathrm{b}}$ & $3.24^{a}$ & $3.08^{a}$ & 0.10 \\
\hline
\end{tabular}

Within a row, means denoted with different letter are statistically different $(\mathrm{P}<0.05)$. LSM: Least square mean. SE: Standard error. 
Compared to raw meat, cooking leads to a significant loss of moisture $(\mathrm{P}<0.05)$ (Table 1$)$. However, no statistically significant differences were found between methods of heat treatment, where decrease in moisture level for roasted and microwaved meat was similar and amounted $14.42 \%$ $14.56 \%$ respectively. Maranesi et al. (2005) comparing the lambs stakes heated in microwave or broiled to the internal temperature of $75^{\circ} \mathrm{C}$ also observed the moisture loss of $12.2 \%$ and $13.7 \%$ respectively compared to raw meat, whereas the treatment method did not significantly affect the water content in cooked meat. The similar results regarding moisture loss due to thermal treatment were obtained by Badiani et al. (2004) by heating in convection oven lamb lean loins to the core temperature $75^{\circ} \mathrm{C}$. While Alfaia et al. (2010) found a significantly larger loss of moisture in beef processed in a microwave compared to meat subjected to boiling or grilling. The results of expressed juice indicates that losses of own water in the meat after thermal treatment were significantly lower $(\mathrm{P}<0.05)$ than in raw meat (Table 1). The cooking method did not affect the expressed juice, although the roasted meat was characterized by the slightly better value of this feature. In the studies on foal meat Lorenzo et al. (2015) observed the lower water holding capacity for samples cooked in the microwave than in meat subjected to roasting grilling or frying.

Compared to raw meat the thermal procedures resulted in significant increase of intramuscular fat, protein and collagen content (Table 1). The mean values obtained in the presented study are in agreement with those reported by Badiani et al. (2004), who also showed an increase in protein and fat concentration in meat under the influence of heat treatment. Also Maranesi et al. (2005) found an increase in protein and fat content after microwaving or broiling lamb meat compared to raw samples, without significant differences between the used cooking procedures.

The analysis of meat color changes under the influence of heat treatment indicates that the samples cooked in microwave or roasted were brighter $(\mathrm{P}<0.05)$ (higher $\mathrm{L}^{*}$ values) in comparison to raw meat (Table 2). Moreover, the brighter color of cooked samples was also confirmed by lower $\mathrm{C}^{*}$ values (more distant to the $\mathrm{L}^{*}$ axis of the CIE-LAB System). It was also characterized by higher value of $\mathrm{b}^{*}$ (yellowness) $(\mathrm{P}<0.05)$. However, the value of $\mathrm{a}^{*}$ parameter (redness) was lower in the cooked meat. The higher values of $\mathrm{H}^{*}$ indicated the color of the cooked samples was more yellow (closer to the $\mathrm{b}^{*}$ axis of the CIE color-space) compared to raw meat. The statistically higher value $(\mathrm{P}<0.05)$ of this parameter was observed for roasted meat compared to microwaved samples. Many consumers believe that the meat color after heat treatment is an indicator of doneness, and that safety from microbal standpoint has been attained (Sen et al., 2014). The meat color is primarily determined by myoglobin and its reactions of oxygenation, oxidation and reduction during cooking procedures (Pathare and Roskilly, 2016). According to Liu et al. (2013) meat with increasing heating temperature tends to take a brighter color. This is due to expended reflection of light, emerging from light scattering by denatured proteins.

The most represented fatty acids in the lipids extracted from the raw meat, in descending order of concentration, were oleic, palmitic and stearic acids (C18:1 $c), \mathrm{C} 16: 0$ and C18:0, respectively), totaling $82.04 \%$ of all determined acids. The dominant acids in the PUFA group were linoleic acid (C18: 2c9, c12), the content of which was the highest in the group of acids belonging to the $n-6$ family, while in the n-3 family the most was linolenic acid (Table 3). The similar order of importance of the main fatty acids in intramuscular fat of the raw lean were reported by others in lambs of different breeds and slaughter weight (Badiani et al., 2004; Bolte et al., 2002; Maranesi et al., 2005; Radzik-Rant et al., 2014; Sañudo et al., 2000; Wachira et al., 2002).

Heat treatment of the tested samples did not change the content of SFA and MUFA acids in comparison to raw meat (Table 4). Although the share of these acid groups sum increased in both roasted and microwaved meat, the differences were not statistically significant. Only the sum of PUFA decreased $(\mathrm{P}<0.05)$ for the microwave treatment. In PUFA n- 6 the content of C18:2 and C20:4 decreased $(\mathrm{P}<0.05)$ only for microwave but content of C20: 3 significantly decreased in both cooking methods. In the n-3 group, the content of C22: 5 (DPA) also decreased significantly under the influence of roasting and microwave (Table 3 and 4). Maranesi et al. (2005) in

Table 2: Effect of cooking method on meat color

\begin{tabular}{|c|c|c|c|c|}
\hline \multirow[t]{2}{*}{ Trait } & Raw meat $(n=24)$ & Microwaving $(n=24)$ & Roasting $(n=24)$ & SE \\
\hline & LSM & LSM & LSM & \\
\hline $\mathrm{L}^{*}$ (lightness) & $36.50^{b}$ & $48.44^{a}$ & $51.31^{a}$ & 0.79 \\
\hline$a^{*}$ (redness) & $19.05^{b}$ & $12.71^{\mathrm{a}}$ & $11.45^{\mathrm{a}}$ & 0.33 \\
\hline$b^{*}$ (yellowness) & $2.90^{b}$ & $12.08^{a}$ & $12.46^{\mathrm{a}}$ & 0.21 \\
\hline$C^{*}$ & $19.30^{b}$ & $17.57^{\mathrm{a}}$ & $16.94^{\mathrm{a}}$ & 0.34 \\
\hline $\mathrm{H}^{*}$ & $8.53^{c}$ & $43.66^{a}$ & $47.52^{b}$ & 0.66 \\
\hline
\end{tabular}

Within a row, means denoted with different letter are statistically different $(P<0.05)$. LSM: Least square mean. SE: Standard error. 
Rant, et al.

Table 3: Effect of cooking method on fatty acid composition $(\mathrm{g} / 100 \mathrm{~g}$ total fatty acid)

\begin{tabular}{|c|c|c|c|c|}
\hline \multirow[t]{2}{*}{ Fatty acid } & Raw meat $(n=24)$ & Microwaving $(n=24)$ & Roasting $(\mathrm{n}=24)$ & \multirow[t]{2}{*}{ SE } \\
\hline & LSM & LSM & LSM & \\
\hline C10:0 & 0.10 & 0.11 & 0.10 & 0.01 \\
\hline C12:0 & 0.09 & 0.08 & 0.09 & 0.01 \\
\hline $\mathrm{C} 14: 0$ & 1.86 & 2.18 & 1.91 & 0.14 \\
\hline C15:0 & 0.43 & 0.42 & 0.48 & 0.04 \\
\hline C16:0 & 22.71 & 24.83 & 22.60 & 0.76 \\
\hline $\mathrm{C} 17: 0$ & 1.77 & 1.72 & 1.85 & 0.19 \\
\hline C18:0 & 20.37 & 19.18 & 20.65 & 0.93 \\
\hline C20:0 & 0.13 & 0.12 & 0.13 & 0.01 \\
\hline C14:1 & 0.06 & 0.07 & 0.06 & 0.00 \\
\hline C16:1 & 2.08 & 2.18 & 2.14 & 0.07 \\
\hline C17:1 & 0.86 & 0.85 & 0.96 & 0.10 \\
\hline $\mathrm{C} 18: 1 \Sigma-t$ & 2.35 & 2.05 & 2.64 & 0.36 \\
\hline C18:1n9c & 38.96 & 40.60 & 39.52 & 0.94 \\
\hline C18:1n7c & 1.32 & 1.23 & 1.27 & 0.07 \\
\hline C20:1 & 0.10 & 0.12 & 0.10 & 0.01 \\
\hline C18:25- $t$ & 0.10 & 0.09 & 0.12 & 0.01 \\
\hline C18:2n-6c & $4.57^{b}$ & $3.15^{a}$ & $3.84^{a}$ & 0.51 \\
\hline C18:3n-3 & 0.37 & 0.28 & 0.31 & 0.04 \\
\hline C20:3n-6 & $0.11^{\mathrm{b}}$ & $0.06^{a}$ & $0.07^{a}$ & 0.01 \\
\hline C20:4n-6 & $1.10^{\mathrm{b}}$ & $0.35^{a}$ & 0.72 & 0.18 \\
\hline C20:5n-3 & 0.12 & 0.08 & 0.09 & 0.02 \\
\hline$C 22: 5 n-3$ & $0.38^{b}$ & $0.28^{a}$ & $0.31^{a}$ & 0.03 \\
\hline C22:6n-3 & 0.16 & 0.15 & 0.15 & 0.00 \\
\hline C18:2c9t11 & 0.23 & 0.17 & 0.23 & 0.03 \\
\hline
\end{tabular}

Within a row, means denoted with different letter are statistically different $(P<0.05)$. LSM: Least square mean. SE Standard error.

Table 4: Effect of cooking methods on partial sums of fatty acids and fatty acid ratios ( $\mathrm{g} / 100 \mathrm{~g}$ total fatty acid)

\begin{tabular}{|c|c|c|c|c|}
\hline \multirow[t]{2}{*}{ Trait } & Raw meat $(n=24)$ & Microwaving $(n=24)$ & Roasting $(n=24)$ & \multirow[t]{2}{*}{ SE } \\
\hline & LSM & LSM & LSM & \\
\hline$\Sigma$ SFA & 47.44 & 48.64 & 47.79 & 0.79 \\
\hline$\Sigma$ MUFA & 45.73 & 47.11 & 46.69 & 0.85 \\
\hline$\Sigma$ PUFA & $7.13^{b}$ & $4.60_{a}$ & 5.84 & 0.53 \\
\hline$\Sigma n-6$ & $5.77^{b}$ & $3.56^{a}$ & 4.63 & 0.48 \\
\hline$\Sigma \mathrm{n}-3$ & $1.02^{b}$ & $0.79^{a}$ & 0.86 & 0.06 \\
\hline$n-6 / n-3$ & 5.59 & 4.43 & 5.30 & 0.34 \\
\hline PUFA/SFA & $0.15^{b}$ & $0.10^{\mathrm{a}}$ & 0.12 & 0.01 \\
\hline
\end{tabular}

Within a row, means denoted with different letter are statistically different $(P<0.05)$. LSM : Least square mean, SE: Standard error, SFA: Saturated fatty acid, MUFA: Monounsaturated fatty acid, PUFA: Polyunsaturated fatty acid.

roasted and microwaved lamb meat obtained statistically significant increase in SFA and, similarly to the present studies, no differences in MUFA content. The authors also noted a decrease in PUFA content, for roasted and heated meat in the microwave by $7.9 \%$ and $5.9 \%$ respectively. In our studies, the reduction in the content of this group of acids was on a higher level, during roasting by $22.1 \%$, in the microwave by $55.4 \%$. Similar to these results, a decrease in the PUFA content of about $51.9 \%$ in roast beef meat was obtained by de Oliveira et al. (2015). In turn, Alfaia et al. (2010) in the studies of the influence of heat treatment on beef a decrease in the content of PUFA $\mathrm{n}-6$ and $\mathrm{n}-3$, an increase in the content of saturated acids (C14:0, C16:0, C18:0) and oleic acid have been noticed. While cooking of lamb meat in the studies of Badiani et al.
(2004) did not cause changes in the fatty acid profile. Only the C15:0 content was significantly higher in cooked meat in comparison to raw meat.

Changes in the content of polyunsaturated fatty acids obtained in this study could be due to the higher susceptibility of these acids to oxidative degradation relative to other acids. Lower oxidative stability is associated with the presence of double bonds, which are more vulnerable to oxygen attack (Alfaia et al., 2010, Clausen and Ovesen, 2005). Degradation of PUFAs in the microwave resulted in a reduction $(\mathrm{P}<0.05)$ of the PUFA/SFA ratio, while it did not change the $n-6 / n-3$ ratio (Table 4$)$. Similar to these results were obtained by Alfaia et al. (2010) in beef meat and Maranesi et al. (2005) in lamb meat. 
Heat treatment of meat in the tested samples did not show significant changes in the content of the main conjugated linoleic isomer C18: $2 \imath, t 11$. The smallest content of this isomer was obtained in the microwave but the differences compared to roasted and raw meat were not statistically significant (Table 3). The lack of changes in the share of this biologically active ingredient in ruminant meat under the influence of cooking is of great importance from the point of view of human health. The C18: $2 c 9, t 11$ (CLA) isomer supplied in an amount of about $400 \mathrm{mg}$ per day may contribute to the effective prevention of cancers and vascular diseases (Griswold et al., 2003). Lack of changes in CLA content under the influence of cooking method of both lamb and beef meat was also noted by Alfaia et al. (2010), Badiani et al. (2004), Maranesi et al. (2005) and Sarriés et al. (2009). According to Yang et al. (2000), the oxidative stability of CLA isomers is determined by their cis and trans configuration, but not by the position of a double bond. The same authors state that cis/cis isomers are more relatively susceptible to oxidative degradation than cis/trans or trans/trans isomers because oxygen radicals more attack cis double bonds than trans configuration.

\section{CONCLUSION}

According to results the cooking loss was greater in lamb meat subjected to heating in the microwave than in roasting. Both cooking methods used did not differ in terms of their impact on the increase in fat, protein and collagen content compared to raw meat. Relative to uncooked meat, that cooked by microwaves or by roasting had a lighter color with greater redness and greater yellowness.

The cooking methods used in the study did not cause significant changes in the SFA and MUFA content. The PUFA content and PUFA/SFA ratio decreased only in lamb meat heated in the microwave but the content of some acids like C20:3 and C22:5 (DPA) decreased both under the influence of microwave and roasting. Both cooking methods no effect on significant change in the content of the $\mathrm{C} 18: 2 c, t 11$ isomer, which is very important in the human diet.

The obtained results suggest that both cooking methods could be recommended for quick preparation of lamb meat dishes, although in terms of meat quality roasting was slightly better than cooking in the miocrowave.

\section{Author contributions}

W.R. performed the research, analyzed the data, conducted statistical data analysis and wrote the paper; A.R-R. conceived and designed the study, performed the research, wrote the paper and assumed primary responsibility for the final content; M.Ś. performed the research, analyzed the data; R.N. conceived and designed the study, supported the design of the study, critically revised the paper; Ż.S. performed the research; M.Śl. performed the research. A.M-V. performed the research; All the authors have read and approved the final manuscript.

\section{REFERENCES}

Aaslyng, M. D., C. Bejerholm, P. Ertbjerg, H. C. Bertram and H. J. Andersen. 2003. Cooking loss and juiciness of pork in relation to raw meat quality and cooking procedure. Food Qual. Prefer. 14: 277-288.

Alfaia, C. M. M., S. P. Alves, A. F. Lopes, M. J. E. Fernandes, A. S. H. Costa, C. M. G. Fontes, M. L. F. Castro, R. J. B. Bessa and J. A. M. Prates. 2010. Effect of cooking methods on fatty acids, conjugated isomers of linoleic acid and nutritional quality of beef intramuscular fat. Meat Sci. 84: 769-777.

Badiani, A., L. Montellato, D. Bochicchio, P. Anfossi, E. Zanardi and M. Maranesi. 2004. Selected nutrient contents, fatty acid composition, including conjugated linoleic acid, and retention values in separable lean from lamb rib loins as affected by external fat and cooking method. J. Agric. Food Chem. 52: 5187-5194.

Biesalski, H. K. 2005. Meat as a component of a healthy diet-are there any risks or benefits if meat is avoided in the diet? Meat Sci. 70: 509-524.

Bolte, M. R., B. W. Hess, W. J. Means, G. E. Moss and D. C. Rule. 2002. Feeding lambs high-oleate or high-linoleate safflower seeds differentially influences carcass fatty acid composition. J. Anim. Sci. 80: 609-616.

Bou, R., F. Guardiola, A. Grau, S. Grimpa, A. Manich and A. Barroeta. 2001. Influence of dietary fat source, a-tocopherol, and ascorbic acid supplementation on sensory quality of dark chicken meat. Poult. Sci. 80: 800-807.

Clausen, J. L. and L. Ovesen. 2005. Changes in fat content of pork and beef after pan-frying under different conditions. J. Food Compos. Anal. 18: 201-211.

Corcoran, K., A. Bernu, E. Manrique, T. Pacchioli, R. Baines and J. P. Boutonnet. 2001. Current consumer attitudes towards lamb and beef in Europe. Options Mediterr. Ser. A Semin. Mediterr. 46: 75-79.

De Oliveira, E. A., A. A. M. Sampaio, W. Henrique, T. M. Pivaro, B. L. Rosa and A. R. M. Fernandes. 2015. Chemical and fatty acid composition of different cuts cooked or uncooked from yearling bulls fed oil sources. Acta Sci. Anim. Sci. 37: 187-194.

Dominguez, R., M. Gomez, S. Fonseca and J. M. Lorenzo. 2014. Effect of different cooking methods on lipid oxidation and formation of volatile compounds in foal meat. Meat Sci. 97: 223-230.

Folch, J., M. Lees, and S. G. H Stanley. 1957. A simple method for the isolation and purification of total lipids from animal tissues. J. Biol. Chem. 226: 497-509.

Gerber, N., M. R. L. Scheeder and C. Wenk. 2009. The influence of cooking and fat trimming on the actual nutrient intake from meat. Meat Sci. 81: 148-154.

Grau, R. and R. Hamm. 1953. Eine einfache methode zur bestimmung der wasserbindung im muskel. Naturwissenschaften. 40: 29-30.

Griswold, K. E., G. A. Apgar, R. A. Robinson, B. N. Jacobson, D. Johnson and H. D. Woody. 2003. Effectiveness of short-term feeding strategies for altering conjugated linoleic acid content of beef. J. Anim. Sci. 8: 1862-1871. 
Kondjoyan, A., A. Kohler, C. E. Realini, S. Portanguen, R. Kowalski, S. Clerjon, P. Gatellier, S. Chevolleau, J. Bonny and L. Debrauwe. 2014. Towards models for the prediction of beef meat quality during cooking. Meat Sci. 97: 323-331.

Li, C., D. Wang, H. Dong, W. Xu, F. Gao, G. Zhou and M. Zhang. 2013. Effects of different cooking regimes on the microstructure and tenderness of duck breast muscle. J. Sci. Food Agric. 93: 1979-1985.

Liu, F., L. Meng, X. Gao, X. Li, H. Luo and R. Dai. 2013. Effect of end point temperature on cooking losses, shear force, color, protein solubility and microstructure of goat meat. J. Food Process. Preserv. 37: 275-283.

Lorenzo, J. M., A. Cittadini, P. E. Munekata and R. Domínguez. 2015. Physicochemical properties of foal meat as affected by cooking methods. Meat Sci. 108: 50-54.

Mancini, R. A. and M. Hunt. 2005. Current research in meat color. Meat Sci. 71: 100-121.

Maranesi, M., D. Bochicchio, L. Montellato, A. G. Zaghini, G. Pagliuca and A. Badiani. 2005. Effect of microwave cooking or broiling on selected nutrient contents, fatty acid patterns and true retention values in separable lean from lamb rib-loins, with emphasis on conjugated linoleic acid. Food Chem. 90: 207-218.

Nikmaram, P., M. S. Yarmand, Z. Emamjomeh and H. K. Darehabi. 2011. The effect of cooking methods on textural and microstructure properties of veal muscle (Longissimus dorsi). Glob. Vet. 6: 201-207.

Nuernberg, K., A. Fisher, G. Nuernberg and D. Dannenberger. 2008. Meat quality and fatty acids composition of lipids in muscle and fatty tissue of scudde lambs fed grass versus concentrate. Small Rumin. Res. 74: 279-283.

Pathare, P. B. and A. P. Roskilly. 2016. Quality and energy evaluation in meat cooking. Food Eng. Rev. 8: 435-447.

Pereira, P. M. and A. F. Vicente. 2013. Meat nutritional composition and nutritive role in the human diet. Meat Sci. 93: 586-592.

Radzik-Rant, A., W. Rant, M. Gajda and A. Pokrop. 2014. The fatty acid profile of muscle tissue of ram lambs with diverse genotypes. Folia Biol. (Krakow). 62: 103-108.

Sañudo, C., M. E. Enser, M. M. Campo, G. R Nute, G. Marı'a, I. Sierra and J. D. Wood. 2000. Fatty acid composition and sensory characteristics of lamb carcasses from Britain and Spain. Meat Sci. 54: 339-346.

Sarriés, M. V., B. E. Murray, A. P. Moloney, D. Troy and M. J. Beriain.
2009. The effect of cooking on the fatty acid composition of longissimus muscle from beef heifers fed rations designed to increase the concentration of conjugated linoleic acid in tissue. Meat Sci. 81: 307-312.

Schmid, A., M. Collomb, R. Sieber and G. Bee. 2006. Conjugated linoleic acid in meat and meat products: A review. Meat Sci. 73: 29-41.

Sen, A. R., B. M. Naveena, M. Muthukumar and S. Vaithiyanathan. 2014. Color, myoglobin denaturation and storage stability of raw and cooked mutton chops at different end point cooking temperature. J. Food Sci. Technol. 51: 970-975.

Serrano, A., J. Librelotto, S. Cofrades, F. J. Sánchez-Muniz and F. Jiménez-Colmenero. 2007. Composition and physicochemical characteristics of restructured beef steaks containing walnuts as affected by cooking method. Meat Sci. 77: 304-313.

SPSS Base 23.0. 2016. Users Guide, SPSS Inc. Available from: http://www.public.dhe.ibm.com. [Last accessed on 2018 Jun 11].

Tholstrup, T., P. Marckmann, J. Jespersen and B. Sandstrom. 1994. Fat high in stearic acid favorably affect blood lipids and factor VII coagulant activity in comparison with fat high in palmitic or high in myristic and lauric acids. Am. J. Clin. Nutr. 59: 371-377.

Tornberg, E. 2005. Effect of heat on meat proteins-implications on structure and quality of meat products: A review. Meat Sci. 70: 493-508

Wachira, A. M., L. A. Sinclair, R. G. Wilkinson, M. Enser, J. D. Wood and A. V. Fisher. 2002. Effects of dietary fat source and breed on the carcass composition, n-3 polyunsaturated fatty acid and conjugated linoleic acid content of sheep meat and adipose tissue. Br. J. Nutr. 88: 697-709.

Wood, J. D., R. I. Richardson, G. R. Nute, A. V. Fisher, M. M. Campo and E. Kasapidou. 2008. Effects of fatty acids on meat quality: A review. Meat Sci. 78: 343-358.

Yang, L., L. K. Leung, Y. Huang and Z. Y. Chen. 2000. Oxidative stability of conjugated linoleic acid isomers. J. Agric. Food Chem. 48: 3072-3076.

Yarmand, M. S. and A. Homayouni. 2009. Effect of microwave cooking on the microstructure and quality of meat in goat and lamb. Food Chem. 112: 782-785.

Yarmand, M. S., P. Nikmaram, Z. Emamjomeh and A. Homayouni. 2013. Microstructural and mechanical properties of camel longissimus dorsi muscle during roasting, braising and microwave heating. Meat Sci. 95: 419-424. 